\title{
Journal of ETA Maritime Science
}

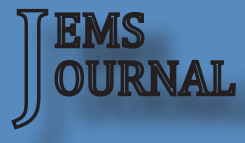

\section{Industrial Perspective}

\section{Gemi Finansman Kredi Sözleşmelerinde Değerleme ve Yeniden Değerleme Riski}

\author{
Ahmet Yaşar CANCA \\ İnce Denizcilik \\ ycanca@incedeniz.com
}

\begin{abstract}
$\ddot{O} z$
Gemilerin satın alımları sırasında kullanılan yatırım kredileri, uzun vadeli krediler olup, bu kredinin tespitinde gemi bedelinin değerlemesi esas alınmaktadır. Kredi veren kurumlar krediyi verirken istedikleri finansal güvencelerin korunması amacılla yatırım sözleșmelerine "değer koruması" (assetprotection) maddesi koyarak, krediye konu geminin istenilen zamanlarda yeniden değerlemesini isteyebilmektedir. Yeniden değerleme sonrası finansal güvencede bir eksiklik olursa borçludan bunun tamamlaması istenmektedir. Bahse konu kredi sözleșmelerinin maddelerinde açılanan "yeniden değerleme" yöntemleri, kredi kullanan işletmelere bazen firsatlar sunarken bazen de tehditler oluşturabilmektedir. Bu nedenle sözleșmedeki "yeniden değerleme" durumunun çok iyi bir şekilde incelenmesi gerekmektedir. Konunun daha iyi anlaşılabilmesi amacıyla, kredi faizi, komisyon vb. ticari terimler yazının kapsamı dışında bırakılmıştır.
\end{abstract}

Anahtar Kelimeler: Gemi Finansmanı, Yatırım Kredisi, Yeniden Değerleme

\section{The Risk of Valuation and Revaluation in the Ship Finance Loan Agreements}

\section{Abstract}

Ship loan credits used during the purchase of ships is considered to be long-term finance credits and their amounts are determined according to the valuation of the ship they are concerned with. The value of the ship determined at the time loan agreement is signed, goes under a "revaluation" process at the debt payment period. Even sometimes the "revaluation" methods mentioned in the bank loan agreements can bring beneficial opportunities to borrower shipping companies, they can also become serious financial threats in the long run. This is why a detailed and an accurate examination of the term "revaluation" is crucial when talking about the financial loan agreements. In this paper the possible financial threats within the valuation process of a ship is tried to be clarified within three different scenarios, with different examples. To be able to focus on the issue, financial terms such as "interest" and "commission" is not taken into the paper's context. 


\section{Giriş}

Kredi veren işletmeler verdiği kredilerin geri ödenebilmesini garanti altına almak ister. $\mathrm{Bu}$ konuda sermayedarlarına karşı sorumlu olup, gerekli önlemleri almak zorundadır. Gemi satın alma kredilerinin geri ödenebilmesi garantileri için kredi veren işletmelerin kullandığı yöntemler sözleşmelerde "security" veya " covenants" olarak tanımlanmaktadır. Bular sıralanacak olursa;

- Kredi veren kurum, kredi verilecek olan borçlu ile bir çeşit ortaklık yapar. $\mathrm{Bu}$ ortaklığa borçlunun da belirli oranda sermaye koymasını istenir. $\mathrm{Bu}$ oran \% 30 borçlu, \% 70 kredi veren işletme şeklindedir (bu oranların geçmişte \% 20 borçlu, \% 80 kredi veren şeklinde uygulandığı durumlarda bulunmaktadir).

- Belli miktarda paranın rehin olarak tutulması. Bu para miktarı bankaların merkez bankalarına yatırmak zorunda oldukları zorunlu karşılık miktarından daha az olmamaktadır. Uygulamada, zorunlu karşılığın 2 katı miktarında bir meblağ rehin alınmaktadır.

- Kredi veren kurum, gemi işletilirken elde ettiği navlun gelirlerini kendi bankası üzerinden geçirilmesini talep eder.

- Kredi miktarının \% 120 si oranında finansal ipotek alınır. Gemi üzerine kredinin \% 100 oranında 1.sırada ipotek konur ve geri kalan kısım ya ipotek konulabilecek başka bir gemi üzerine 2.sırada ipotek konur yada uluslararası geçerliği olan ilave ipotek istenir.

- Borçlu şirketlerden (anonim şirketler hariç) hissedarların kişisel garantileri de alınir.

- Satın alınması için kredi verilen geminin güvenilir bir sigorta şirketi tarafından sigorta ettirilmesi sağlanarak, sigorta şirketlerince gemi ile ilgili olarak yapılacak her türlü ödemelerde kendilerinin bilgisi ve onayının alınması şartı kredi sözleşmesine konur. Geminin sahibi olduğundan tekne ve makine sigortasının yapacağı her türlü ödeme kredi veren kuruma yapılır eğer kredi veren kurumun yazılı onayı olursa gemi sahibine yapılır. Poliçe üzerinde belirtilen gemi değeri, gemi yeni inşa edilmiş ise kontrat değeridir. İkinci el satın alınmış gemi ise kredi veren kurum tarafından yaptırılan değer tespiti değeridir. Geminin tamamen kayba uğradığı durumlarda, Türk sigorta hukukunda geminin piyasa değeri, İngiliz sigorta hukukunda ise poliçede yazan anlaşılmış değer (agreed value) ödemesi yapılır. Eğer gemi ilk sigorta değeri üzerinden yıllar geçmiş ve kayba uğramışsa İngiliz hukukundaki poliçe değeri sigortalıya ödenir.

Kredinin geri ödenebilmesini garanti altına almak için kullanılan ve yukarıda siralanan yöntemlerden görüldüğü gibi; en önemli unsur gemi bedelinin belirlenmesidir. Esasen burada önemli unsurlardan biri de, kredi miktarı ile kredi verilen gemi bedeli arasındaki ilişkidir. Kredi miktarına esas alınan gemi bedelinin belirlenmesi işlemine "değerleme" adı verilmektedir. $\mathrm{Bu}$ değerlemenin doğru yapılması, kredi veren işletmelerin sermayedarlarına olan sorumluluğudur. Değerleme işleminde kullanılan yöntemleri siralayacak olursak;

- Eşdeğer bir geminin yakın tarihteki satış fiyatı.

- Eğer yakın zamanda satılmış eşdeğer bir gemi yoksa, en az 2 gemi alımsatım brokerinden gemi için alınacak değerleme fiyatı.

- Bağımsız bir sörvey veya değerleme kuruluşuna gemi inceletilerek alınacak değerleme fiyatı.

Yukarıda açıklanan değerleme yöntemlerinden elde edilen fiyatın genellikle \% 70'i kredi miktarı olarak kabul edilir.

Yukarıdaki finansal güvencelerin korunması amaciyla konulmuş koruma maddesi gereği (AssetProtection) ortaklıkla ilgili olarak her yl yeniden 
değerleme yapılması ve ortaklık yapısının bozulmaması konuları kredi sözleșmesine konur. $\mathrm{Bu}$ değerlemeler fiziki kontrollere tabi olmayıp, piyasadaki değerleme olup, yapılmaması veya verilen garantilerin bozulması durumunda kredi veren kurum, borçludan eksik olan güvenceleri tamamlamasını yazılı olarak ister. Sözleşmede borçlunun gerekli teminatları sağlayamaz ise sözleşmeyi ihlal etmiş sayılacağı açık bir şekilde belirtilir.

\section{Yeniden Değerleme Senaryoları}

Gemi alımlarında kullanılan kredi sözleşmelerine konan gemi bedelinin "yeniden değerleme" işlemi üç farklı senaryo olarak karşımıza çıkmaktadır. Birinci senaryo, gemi değerlemesinin aynı kalması. İkinci senaryo, yeniden değerlemenin bir öncekinden daha fazla olması. Üçüncü senaryo, yeniden değerlemenin bir öncekinden daha aşağıda kalması durumu. $\mathrm{Bu}$ senaryoların kredi kullanan ișletmelere olan etkileri aşağıda incelenmiştir.

\subsection{Gemi Değerlemesinin Aynı Kalması Durumu}

Gemi değerlemesinin aynı kalması senaryosu en sorunsuz olan senaryodur. Süreç içerisindeki geminin yıpranması ve yaşlanması vb. sebepler dolayısı ile yaşanan kayıplar, gemi değerindeki yükselmeler ile karşılanmıştır. Yeniden değerlemedeki değişimsizlik, kredi kullanan ile kredi veren arasındaki \%30'a \%70'lik ortaklık dengesinin tekrar oluşturulmasına ihtiyaç duymaz.

\subsection{Gemi Değerlemesinin Bir Öncekinden Daha Fazla Olması Durumu}

Gemi değerinin artması olarak ifade edilebilecek bu senaryo, kredi kullanan işletmenin menfaatinedir. Geminin değerlemesinin bir öncekinden daha fazla olması durumunda, kredi kullanan ile kredi veren arasındaki \%30'a \%70'lik ortaklık dengesinin tekrar oluşturulmasını gerektirir.

$\mathrm{Bu}$ durumu bir örnek ile açıklayacak olursak;

30 milyon USD olarak değerlemesi yapılan bir geminin kredi kullanımı nedeniyle oluşacak ortaklık yapısında (\%30'a \%70'lik) gemi sahibi 9 milyon USD öderken, kredi veren işletme 21 milyon USD ödeme yapar. Ayrıca kredi veren işletme tarafından gemiye konan ipotek ise verilen kredinin \%25 fazlası olan 26,25 milyon USD'dır. Gemi için alınan 10 yıl vadeli 21 milyon USD kredinin yıllık geri ödemesi 2,1 milyon USD'dir.

Geminin yeni değerlemesi 35 milyon USD olarak belirlendiğinde, kredi kullanan ile kredi veren arasındaki \%30'a \%70'lik ortaklık dengesinin tekrar oluşturulması gemi sahibi tarafindan talep edilebilir (yeni kaynak yaratma konusunda kullanılan bir yöntemdir). Yapılan yeni değerlemenin ortaklık oranlarına göre dağılımı; gemi sahibi 10,5 milyon USD, kredi veren işletme 24,5 milyon USD olarak yeniden şekillendirilir. Gemi sahibi ilk yıl kredi taksidini ödemiştir ve kredi borcu, 18,9 milyon USD kalmıştır. Kredi veren ișletmenin ortaklıktaki payı; 18,9/35 oranı ile $\% 75$ 'den \%54'e düşmüștür. Gemi sahibi ilk sözleşmedeki \%70 oranına dönülmesini ister ve kredi sözleşmesine ekyapılarak yeni değerlemeye göre işlem yapılır. $\mathrm{Bu}$ işlem sonucunda kredi veren kuruluşun ortaklık payı, \%70 oran ile 24,5 milyon USD'ye çıkar. Kredi veren işletmenin 24,5 milyon USD yeni ortaklık payı ile kalan 18,9 milyon USD alacağı arasındaki fark, 5.6 milyon USD gemi sahibine ödenir. Gemi sahibinin toplam kredi borcu, 24,5 milyon USD, yıllık ödemesi ise 2,45 milyon USD olmuştur. $\mathrm{Bu}$ yeni kredi sözleşmesi istenirse eski kredinin devamı olarak yapılabildiği gibi, yeni bir kredi sözleşmesi olarak da düzenlenebilir. Fakat kredi süresinin ne olacağı farklı bir değerlendirme konusu olup, kredinin yenilenme süresi konusundaki en önemli etken geminin kredi süresinin sonundaki yaşıdır. Genel kabul gören anlayış geminin ekonomik ömrünün 12 yıl olduğu ve 15 yıla kadar uzatılabileceği gerçeğidir. Kredi süreleri bitiş tarihi olarak geminin 15 yaşını 
geçtiği zaman dilimini geçirilmez. 15 yaşın üstündeki gemiler için en uzun 3 yıl vadeli (genelde 2 yıl) işletme kredisi verilir.

Sonuç olarak gemi sahibi bir anda 5,6 milyon USD'lik bir kaynağa sahip olmuştur. Özellikle deniz ulaștırmasında navlun değerlerinin en yüksek olduğu 20032009 tarihleri arasında bu yöntem gemi sahipleri tarafından defalarca kullanılmış ve yeni gemilerin alınmasına da kaynak oluşturmuştur.

\subsection{Gemi Değerlemesinin Bir Öncekinden Daha Az Olması Durumu}

Gemi değerinin düşmesi olarak ifade edilebilecek bu senaryo, genellikle kriz ve kaza zamanlarında karşılaşılabilen durumdur. Geminin değerlemesinin bir öncekinden daha az olması durumunda, değişim dramatik değil ise ve/veya borçlu borcunu normal ödüyor ise iki tarafta ortaklık dengesinin tekrar oluşturulmasını istemez. Fakat değer düşmesi dramatik olursa, o zaman kredi veren kurum, gemi sahibinden \%30'a \%70'lik ortaklık dengesinin tekrar oluşturulmasını ister.

$\mathrm{Bu}$ durumu önceki örnek üzerinden açıklayacak olursak;

30 milyon USD değerindeki geminin yeni değerleme ile fiyatının 14 milyon USD'a düştüğü tespit edilirse, kredi veren kuruluş ortaklar arasındaki \%30'a \%70'lik ortaklık dengesinin tekrar oluşturulması talep eder.

Bir yılın sonunda 2,1 milyon USD ödeme yapmış olan gemi sahibinin borcu 18,9 milyon USD'dir. Gemi sahibinin borcu gemi değerinden daha fazladır. Kredi veren kurum bu durumda gemi sahibinden sermaye artışı talep eder. Talep yeni oluşan ortaklık dengesine göre belirlenmektedir. Yapılan 14 milyon USD'lik yeni değerlemenin ortaklık oranlarına göre dağılımı; gemi sahibi 4,2 milyon USD, kredi veren işletme 9,8 milyon USD olarak yeniden şekillendirilir.

Kredi veren kurumun 9,8 milyon USD yeni ortaklık payı ile kalan 18,9 milyon USD alacağı arasındaki fark, 9,1 milyon USD'ı sermaye artırımı olarak gemi sahibinden talep eder.
$\mathrm{Bu}$ durum da gemi alınırken 9 milyon USD öz sermaye kullanan gemi sahibi aradan geçen zaman içerisinde 2,1 milyon USD'lik faiz hariç kredi anapara ödemesine rağmen elindeki geminin değeri bankaya olan borcunu karşılamadığını gerçeği ile karşı karşıya kalmaktadır.

\section{Gemi Bedelinin Yeniden Değerlemesi Konusunda Yaşanmış Olaylar}

Örnek 1.

2008 yılında 95.000 DWT'lik bir geminin yeni inşa sözleşme bedeli 63 milyon USD olup, \%20 si (12,6 milyon USD) armatörün öz sermayesinden, 50,4 milyon USD ise yabancı bir bankadan alınan kredi ile karşılanmıştır.

2011 yılında teslim alınan gemi için 2014 yılına kadar 16,2 milyon USD ödeme yapılmış olup, kalan borç 34,2 milyon USD'dir. 2015 yılında yapılan yeniden değerleme sonucu gemi bedeli 19 milyon USD olarak tespit edilmiştir. Kalan borç ile gemi değeri arasındaki fark için gemi sahibinden 1. sırada (\% 100) ipotek için 15,2 milyon USD ipotek alınmıştır. 2 . sıradaki (\% 20) ipotek için ise 7,04 milyon USD ilave ipotek daha istenmiştir. Bu ilave ipotek gemi sahibi tarafından verilemediği takdirde ana taksit ve faizleri düzenli ödediği halde sözleşme iptal edilerek geminin satışı gerçekleştirilecektir.

\section{Örnek 2.}

Bir Türk gemi işletmecisi 2007 yılında her biri 75 milyon USD değerinde 5 adet panamax tipi gemiyi tersaneye sipariş vermiştir. Gemi bedellerinin\%20'sini peşin (15 milyon USD) olarak ödenmiștir. Geriye kalan 60 milyon USD için yabancı bir bankadan alınan kredi kullanılmıştır. 2009 yılında teslim edilen gemiler için kredi veren kurum tarafindan talep edilen \% 120 'lik garanti bedeli 72 milyon USD olup, bu değerin gemi değeri olan 75 milyon USD'den az olması nedeniyle ilave finansal bir ipotekyapılmasına gerek duyulmamıştır. 2014 yılına kadar 5 yıl boyunca, yılda 6 
milyon USD ödeme yapan gemi sahibi, her bir gemi için toplam 30 milyon USD ödeme yapmıștır. 2014 yılı sonunda 60-30=30 milyon USD borç kalmıştır. Kalan borç için kredi veren kurum tarafından talep edilen \% 120 garanti bedeli karşılığı olarak 36 milyon USD'dir

Öte yandan 2014 yılında yapılan yeniden değerlemede gemi bedeli 18 milyon USD olarak tespit edilmiștir. Gemi bedeli istenen ipotek değerini karşılamadığı için gemi sahibi, 36-18=18 milyon USD'lık ilave ipotekler vermesi gerektiği gibi bir durumla karşılaşmıştır. Toplam 5 gemi için verilmesi gereken 90 milyon USD'lık ilave ipoteği verememiş ve gemilerine kredi veren kurum tarafından el konularak satılmıştır.

\section{Sonuç}

Kredi kullanacak gemi sahipleri yeniden değerleme riski nedeni ile borçlanma konusunda ihtiyatlı davranmalıdırlar. $\mathrm{Bu}$ konuda bir ölçü verilebilmesi zordur. Ama 2008 krizinden sonra yaşanan tecrübeler şirketlerin 2 yll gelir elde etmeden borçlarını ödeyebilecek nakit paraya sahip olmadan yeni borçlanmalara gitmemeleri gerektiğini acı bir şekilde öğretmiștir. 


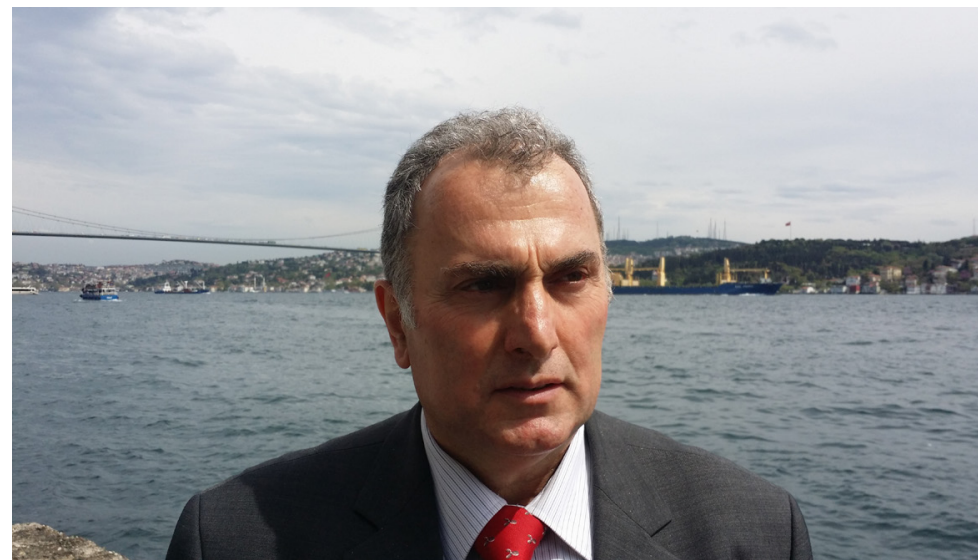

\section{Ahmet Yaşar CANCA' nın Özgeçmişi}

Ahmet Yaşar Canca, 1961 Pazar/Rize doğumlu olup ilk, orta ve lise eğitimini bu ilçede tamamlamıştır. Üniversite eğitimini ise İ.T.Ü Denizcilik Fakültesi Gemi Makineleri İşletme Mühendisliği Bölümünde 1982 yılında tamamlamıştır. Daha sonra İ.Ü. İktisat Fakültesi Çalışma Ekonomisi ve Endüstri İlişkileri Bölümüne girerek buradan da 1987 yılında mezun olmuştur. 1982 - 1994 yılları arasında TDỉ Denizyolları İşletmesi'nde ve özel denizlik işletmelerinde uzakyol vardiya mühendisi, uzakyol 2.mühendisi ve başmühendisi olarak çalışmıştır. 1994 yılında halen çalışmak da olduğu İnce Denizcilik şirketler gurubunda teknik enspektör olarak göreve başladı. Daha sonra "teknik müdür" ve "atanmış kişi" olarak kariyerine devam etti. Canca, İnce Denizcilik'in yatırım ve büyüme konularındaki kararlarında hala etkin rol almaktadır. Canca, sosyoekonomi ve ekonomi-politika konularında yazı ve makaleleri değişik dergi ve internet sitelerinde yayınlanmıştır. İTÜ Denizcilik Fakültesinde 2007 yılından beri "gemi finansmanı" ve YTÜ Gemi İnşaatı ve Denizcilik Fakültesinde "survey yöntemleri" ve "ana makine operasyonları" konusunda öğretim görevlisi olarak dersler vermektedir. Ayrıca denizcilikle ilgili sivil toplum örgütlerinde yönetim kurulu asil ve yedek üye olarak çalışan Canca, 3 dönemdir TMMOB Gemi Makineleri İşletme Mühendisleri Odası Yönetim Kurulu asil üyesi ve saymanı olarak görev yapmaktadır. Bir akademisyenle evli olan yazarımızın iki çocuğu bulunmaktadır. 